\title{
Influence of intensification pressures on pores in die-cast ADC12 alloys
}

\author{
Chun-tao Wang ${ }^{1}$, Jie Yao ${ }^{1}$, Hai-dong Zhao ${ }^{2}$, Run-sheng Yang ${ }^{2}$ \\ 1. Ningbo Heli Mould Technology Co., Ltd., Industrial Park, Xiangshan County, Ningbo 315700, China \\ 2. National Engineering Research Center of Near-net Shape Forming for Metallic Materials, South China University of Technology, \\ Guangzhou 510641, China
}

\begin{abstract}
Die casting process is widely applied in making Al parts. However, due to high speed of liquid metal flow in the die cavity, gases are prone to be entrapped in the filling, resulting in porosity defects. The X-ray computed tomography scanning technique was used to detect the pores in die-cast ADC12 alloys with different intensification pressures. The three-dimensional features of pores including pore size, number, sphericity have been obtained. The effect of different intensification pressures on two different kinds of pores, namely gas-pores and shrinkage pores, was analyzed. The results show that with increasing the pressure, the pore fractions and quantity gradually decrease. When the pressure increased to $85 \mathrm{MPa}$, the pores from gas entrapment during the mold filling were compressed, leading to a lower porosity fraction. The pressure cannot affect the pores in the samples with a thin wall $(2 \mathrm{~mm})$ due to a great solidification rate.
\end{abstract}

Key words: die casting; intensification pressure; porosity; X-ray computed tomography
CLC numbers: TG146.21
Document code: A
Article ID: 1672-6421(2019)03-184-06

$\mathrm{L}$ ightweight has become an inevitable trend in the automotive industry ${ }^{[1,2]}$. Die casting process is widely applied in making Al parts due to great production efficiency, excellent casting surface quality and dimension precision. ADC12 aluminum alloy with excellent castability and superior strength-to-weight ratios is a common die-cast alloy ${ }^{[3,4]}$. However, due to the high speed of liquid metal flow in the die cavity, gases are prone to be entrapped in the filling resulting in porosity defects ${ }^{[5,6]}$. The intensification pressure can strengthen liquid feeding and decrease porosity, hence it is generally believed that the effective application of intensification pressure is crucial to the production of high-integrity parts ${ }^{[7,8]}$.

Conventionally, researchers used the Archimedes method to get the porosity data to study the effect of processing parameters ${ }^{[9,10]}$, or the metallographic method to analyze the distribution of pores and predict

\footnotetext{
*Chun-tao Wang

Male, born in 1983, Bachelor's degree, Senior Engineer. His research interest mainly focuses on material and forming processes such as die-casting, casting, hot-stamping process, and tooling.
}

Received: 2018-12-14; Accepted: 2019-01-28 mechanical properties ${ }^{[11,12]}$. Two-dimension analysis based on the metallographic method overestimates the number and underestimates the size and shape complexity of the casting pores ${ }^{[13-15]}$. Using threedimensional X-ray tomography technique can obtain 3D characteristics of pores, such as size, sphericity and spatial location. Therefore, the technique can describe the characteristics more accurately ${ }^{[16-18]}$.

In this work, samples under three different intensification pressures have been fabricated by the die casting process, and the sample with average pore fraction in each pressure measured by the Archimedes method was inspected by X-ray computed tomography technology. Then the pores in the samples were reconstructed. According to the reconstruction, the effect of intensification pressure on pore characteristics was discussed.

\section{Materials and methods}

The chemical compositions of materials are listed in Table 1 . The casting includes four tensile test specimens with different wall thicknesses of 2, 4, 6, and $8 \mathrm{~mm}$ (Fig. 1). The pouring temperature was $650{ }^{\circ} \mathrm{C}$, and fast shot speed was $2 \mathrm{~m} \cdot \mathrm{s}^{-1}$. Three different intensification 
pressures of 65,75 , and $85 \mathrm{MPa}$ were employed.

In order to characterize the shape and distribution of pores, the X-ray computed tomography inspection was carried out. A resolution of $13.76 \mu \mathrm{m}$ was achieved in the test. Before the X-CT detection, the porosity fractions of samples at each pressure were measured by Archimedes method. Four samples of each condition (wall thickness and pressure) were measured, and one of them closest to the average porosity of all, was selected to be inspected with X-ray CT experiment. Then the scanning data of pores were imported into VG software for 3D reconstruction. The volume, sphericity and spatial distribution of pores can be obtained through the reconstruction.

Table 1: Chemical compositions of ADC12 alloys (wt.\%)

$\begin{array}{ccccccc}\mathrm{Si} & \mathrm{Cu} & \mathrm{Fe} & \mathrm{Zn} & \mathrm{Mn} & \mathrm{Mg} & \mathrm{Al} \\ 9.6-12 & 1.5-3.5 & \leqslant 1.3 & \leqslant 0.1 & \leqslant 0.5 & \leqslant 0.3 & \text { Balance }\end{array}$

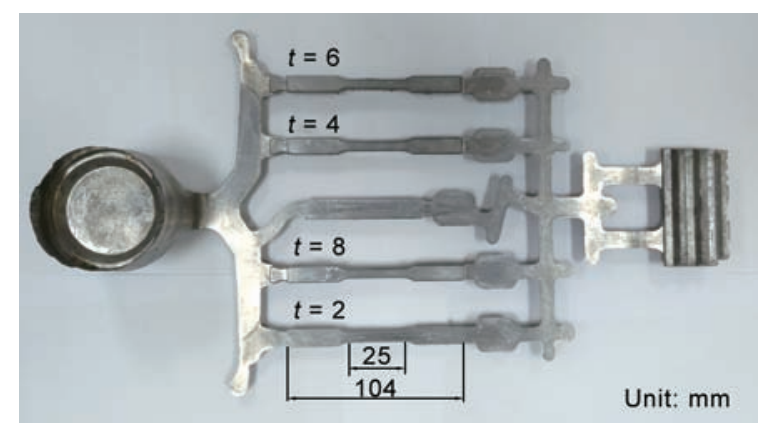

Fig. 1: Four samples with different wall thicknesses $(t)$

\section{Results and discussion}

\subsection{Influence of pressure}

The results of porosity measured by the Archimedes method are summarized in Fig. 2, which shows that the porosity decreased with the increase of intensification pressure, and generally the porosity fractions increased with the wall thickness. Figure 3 exhibits the reconstructed pores in the gauge length of the samples with $8 \mathrm{~mm}$ wall thickness at different intensification pressures. It is obvious that the pores were concentrated in the center and the porosity volumes reduced with increasing the intensification pressure.

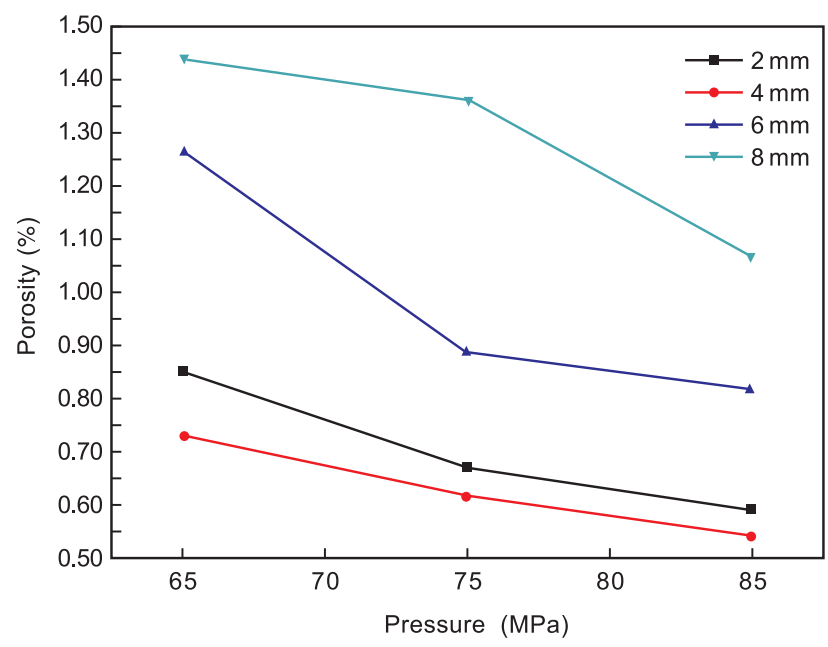

Fig. 2: Porosity of different process parameters with Archimedes method

Figure 4 shows the cumulative volumes of pores in the samples with 2, 4 and $8 \mathrm{~mm}$ wall thicknesses at different intensification pressures. The pressure of $85 \mathrm{MPa}$ has a significantly effect on the decrese of pore volumes. As shown in Figs. 4(b) and 4(c), with increased pressure, the quantity of small pores decreased, showing that the increase of pressure will prevent formation of small pores. For the samples with $8 \mathrm{~mm}$ wall thickness, the sample pore volumes at 75 and $85 \mathrm{MPa}$ are less than that at $65 \mathrm{MPa}$ (Fig. 4c). Figure 5 shows the microstructures of the samples with $6 \mathrm{~mm}$ wall thickness. Pores in conventional die castings can result from gas entrapment, hydrogen segregation from molten metal, and solidification shrinkage. The intensification pressure can compress the entrapped gases and improve the liquid feeding, reducing porosities. Therefore, it can be seen in Fig. 5 that with the increased pressure, the pore number, maximum size, and volume decreased.
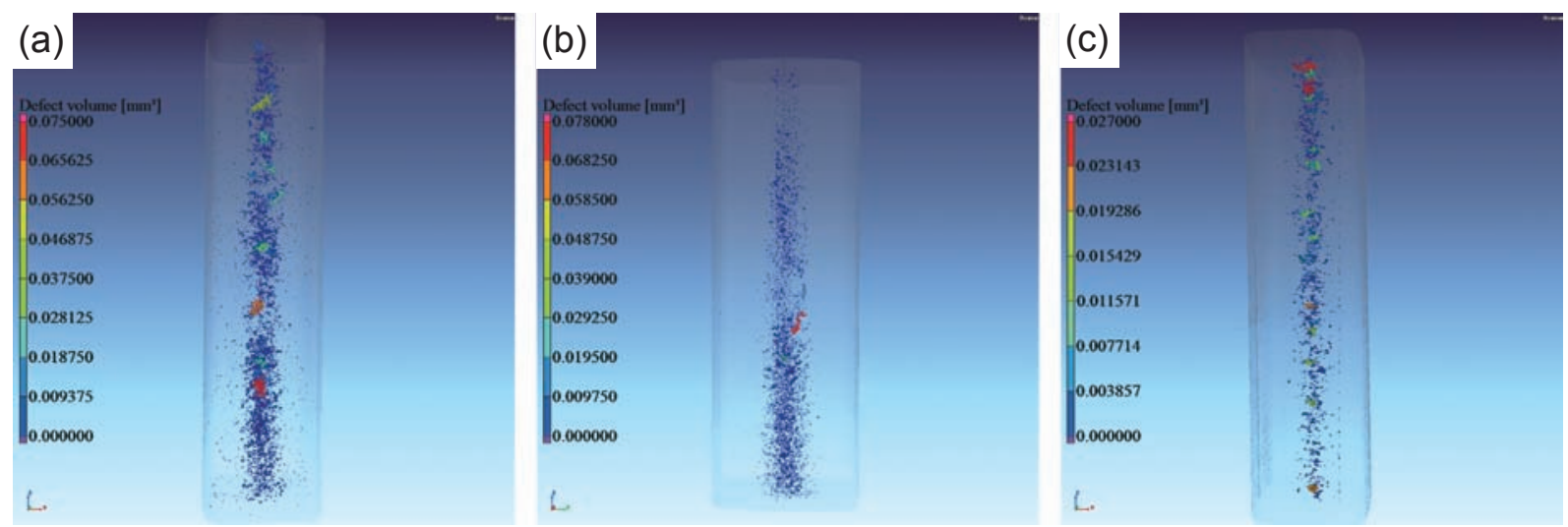

Fig. 3: Distribution of pores in samples with $8 \mathrm{~mm}$ wall thickness at different intensification pressures: (a) $65 \mathrm{MPa}$, (b) $75 \mathrm{MPa}$, (c) $85 \mathrm{MPa}$ 

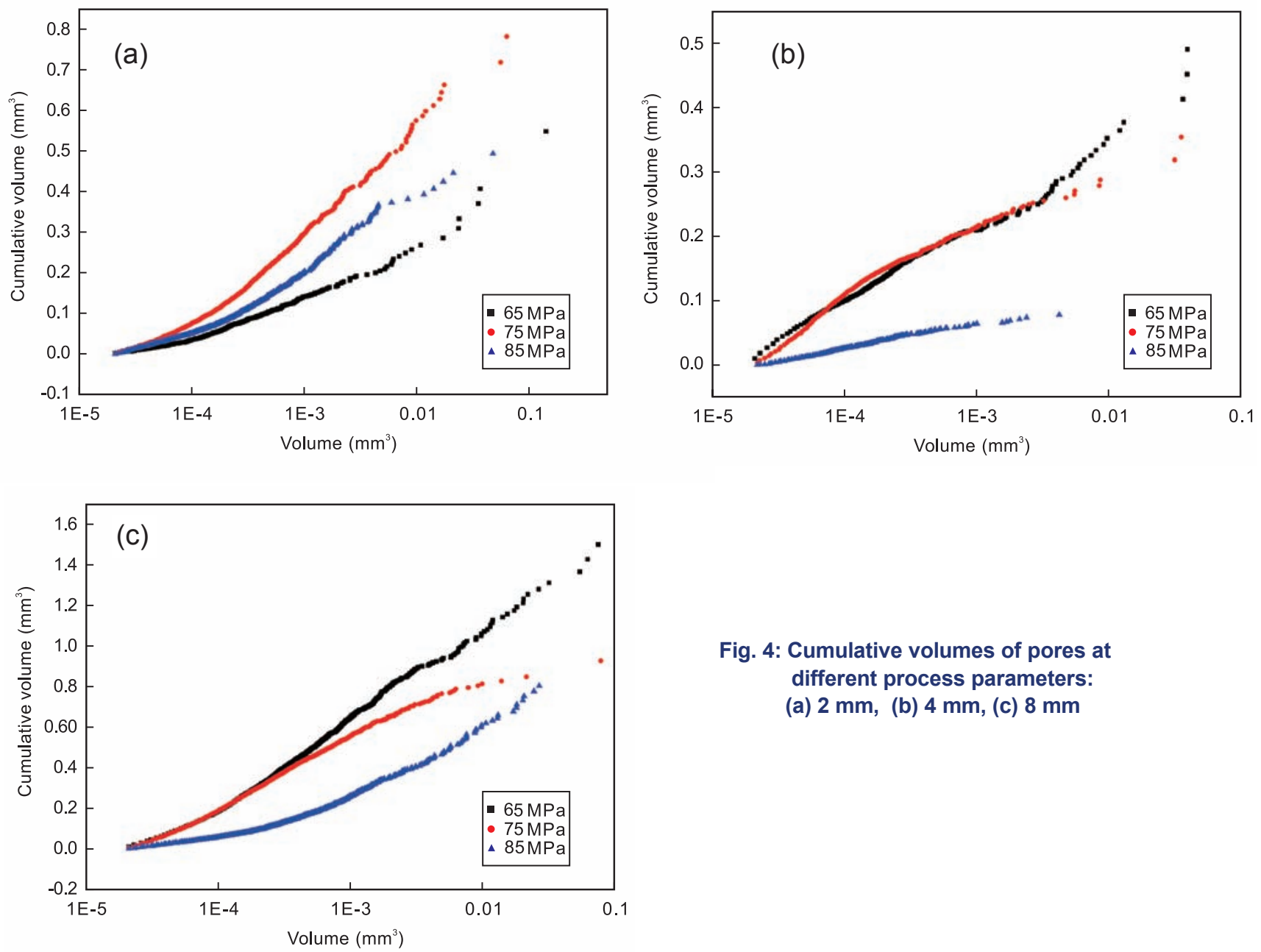

Fig. 4: Cumulative volumes of pores at different process parameters:

(a) $2 \mathrm{~mm}$, (b) $4 \mathrm{~mm}$, (c) $8 \mathrm{~mm}$
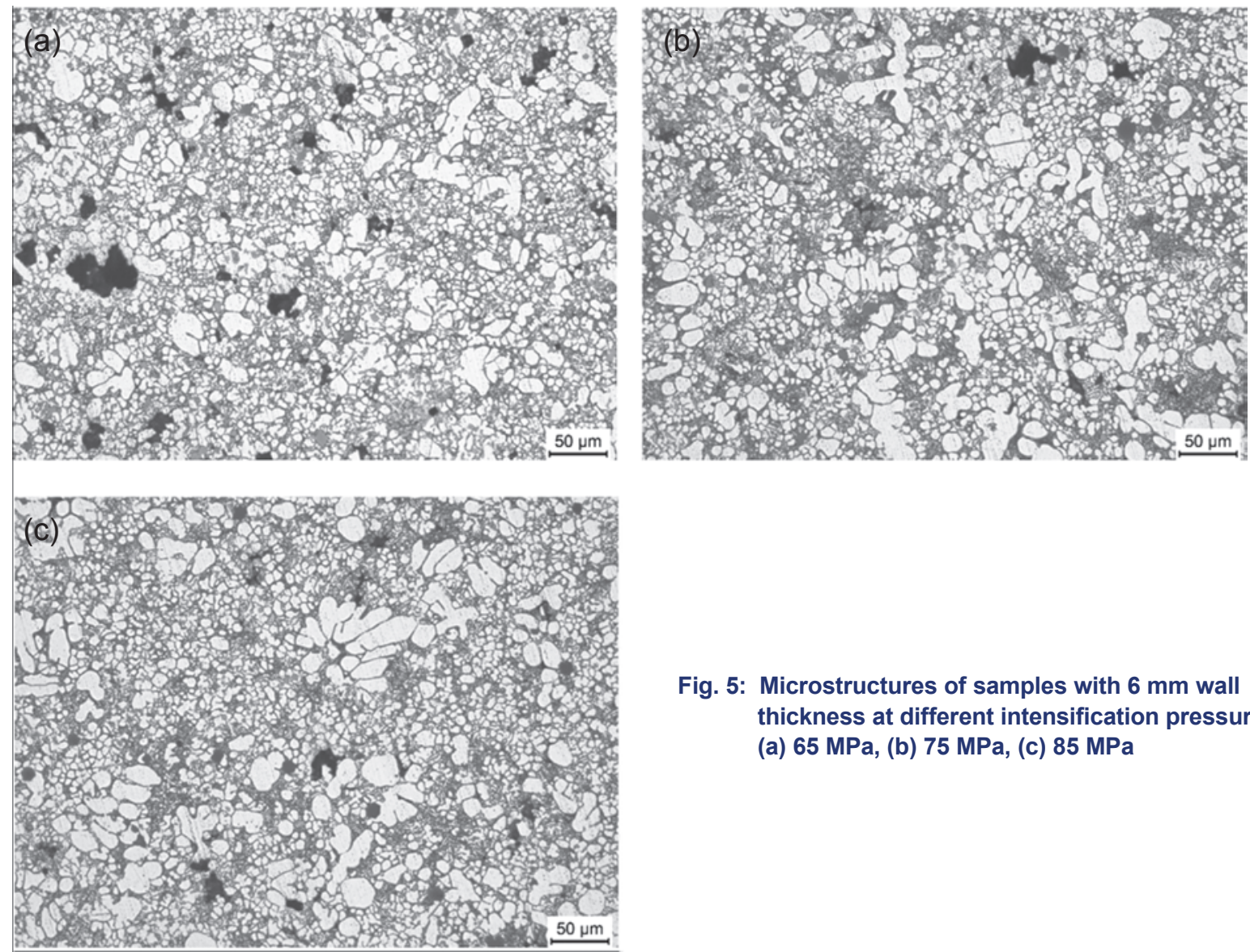

Fig. 5: Microstructures of samples with $6 \mathrm{~mm}$ wall thickness at different intensification pressures: (a) $65 \mathrm{MPa}$, (b) $75 \mathrm{MPa}$, (c) $85 \mathrm{MPa}$ 


\subsection{Influence of wall thickness}

Figure 4(a) indicates that the increasing intensification pressure did not decrease the pores in the samples with $2 \mathrm{~mm}$ wall thickness. Figure 6 shows the reconstructed pores in the samples with 2, 4 and $8 \mathrm{~mm}$ wall thicknesses at the pressure of $85 \mathrm{MPa}$. When the wall thickness is too thin (such as $2 \mathrm{~mm}$ ), the solidification rate is so fast that the inner gate solidified before the application of intensification pressure. In the die casting process, the velocity of liquid filling into thin parts is higher, resulting in more gas entrapment. In addition, the samples with $2 \mathrm{~mm}$ wall thickness are located far from the die cavity center. The Al melt filled the samples later in the mold filling process, hence, more oxides were entrained there. Since the sample is far from the plunger, the pressure transmission from the plunger is limited ${ }^{[9]}$, and the entrained oxide films could be opened during solidification ${ }^{[17,19]}$. Therefore, as for the samples with $2 \mathrm{~mm}$ wall thickness, the effect of intensification pressures on the pores is not apparent, as shown in Fig. 4(a). Also, Fig. 6(a) clearly shows that in the sample, the pores are located in both the sample center and outside parts, confirming the consequence of gas entrapment and oxide film opening.

It is obvious in Fig. 6 that there are some large pores in the sample with $8 \mathrm{~mm}$ wall thickness compared to the sample with $4 \mathrm{~mm}$ thickness (both samples were taken from the die cavity center as shown in Fig. 1). The reasons are that the samples solidified slowly and the transmission time of pressure from the plunger is limited ${ }^{[8]}$, the liquid feeding to the samples at later solidification period was prevented. Since the solidification time of the $8 \mathrm{~mm}$ sample is longer, the pore volume in the $8 \mathrm{~mm}$ sample was greater than that of the $4 \mathrm{~mm}$ sample.
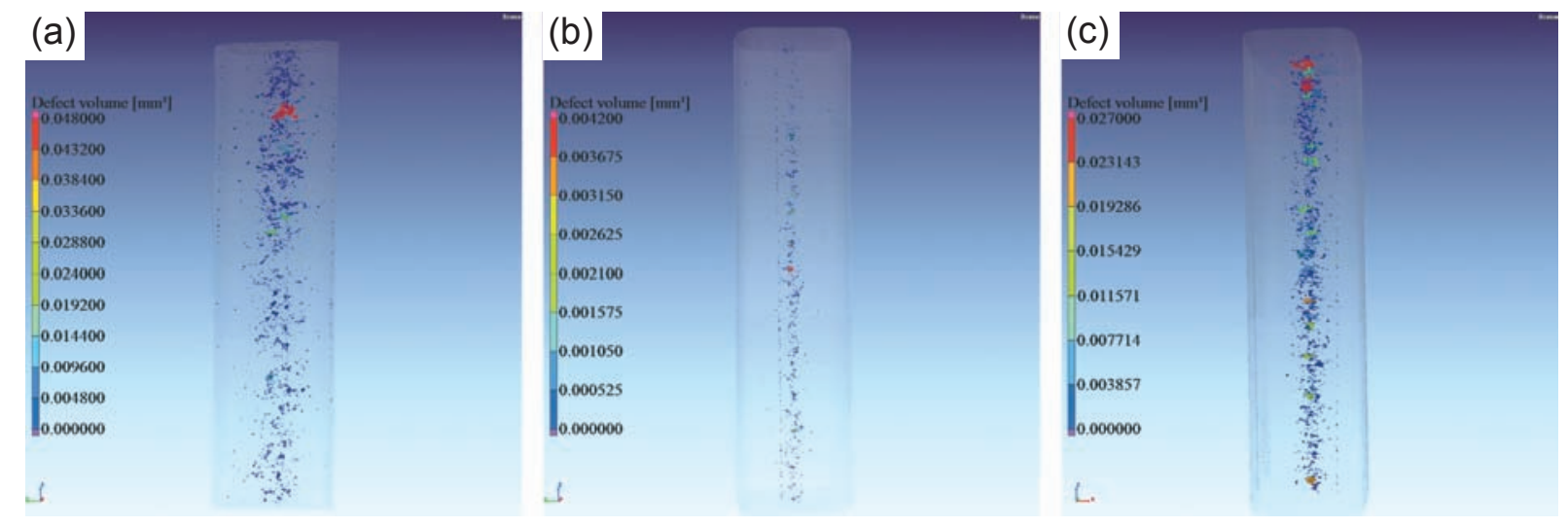

Fig. 6: Distribution of pores with different wall thicknesses at $85 \mathrm{MPa}$ : (a) $2 \mathrm{~mm}$, (b) $4 \mathrm{~mm}$, (c) $8 \mathrm{~mm}$

The average pore volume of the samples with 2,4 and $8 \mathrm{~mm}$ wall thicknesses fabricated by $85 \mathrm{MPa}$ intensification pressure are $4.48 \mathrm{e}^{-4}, 1.03 \mathrm{e}^{-4}$ and $3.68 \mathrm{e}^{-4} \mathrm{~mm}^{3}$, respectively. As discussed above, intensification pressure has little effect on the sample of $2 \mathrm{~mm}$ wall thickness. Since the samples of 4 and $8 \mathrm{~mm}$ thicknesses are located in the die cavity center, the Al melt filled there with a relatively stable flow during the mold filling process. This decreased entrapped gases. Also, the sample solidification times are longer than that of the sample of $2 \mathrm{~mm}$ wall thickness. Hence, the transmission time of intensification pressure is longer, compressing entrapped gases and promoting liquid feed. As a result, there are few gas pores in the former two samples. The porosities in the samples with 4 and 8 $\mathrm{mm}$ wall thicknesses are located in the sample center. It is reasonable that they are dominated by solidification shrinkage. Since the sample of $8 \mathrm{~mm}$ wall thickness has more volumetric shrinkage, the porosities in the sample are more than those in the sample with $4 \mathrm{~mm}$ thickness.

\subsection{Influence of pressure on pore type}

In the samples of $8 \mathrm{~mm}$ wall thickness, the sphericities of pores declined with the increased pressure as shown in Fig. 7.
Sphericity is the ratio of pore surface area to the surface area of equal volume of sphere. The closer the ratio approaches to 1 , the less complex the pore. Researchers ${ }^{[20,21]}$ have done statistical studies on the distribution of pores, and classified the pores according to their sphericity and volume. Pores with sphericity less than 0.5 can be regarded as shrinkage pore affected by the liquid feeding. Therefore, the decline of sphericity in Fig. 7 means that with the pressure increase, gas pores were decreased due to the compression effect on them. This is also confirmed by the microstructures of the $6 \mathrm{~mm}$ samples at different pressures in Fig. 5.

Table 2 shows the variation of pores volumes and numbers of gas and shrinkage pores (classified by the critical sphericity 0.5 ) with increasing intensification pressure. It can be seen that the volume of gas pores is far smaller than that of shrinkage pores, whereas the gas pore quantities are significantly greater at 65 and $75 \mathrm{MPa}$. With the increased pressure, the volume and number of gas pores reduced, but the decline of shrinkage pore volume only happens from the pressure 65 to $75 \mathrm{MPa}$.

Figure 8 shows the cumulative volumes of gas and shrinkage pores in the $8 \mathrm{~mm}$ samples. It can be seen from Fig. 8(a) that when the pressure increased from 65 to $75 \mathrm{MPa}$, the number of 

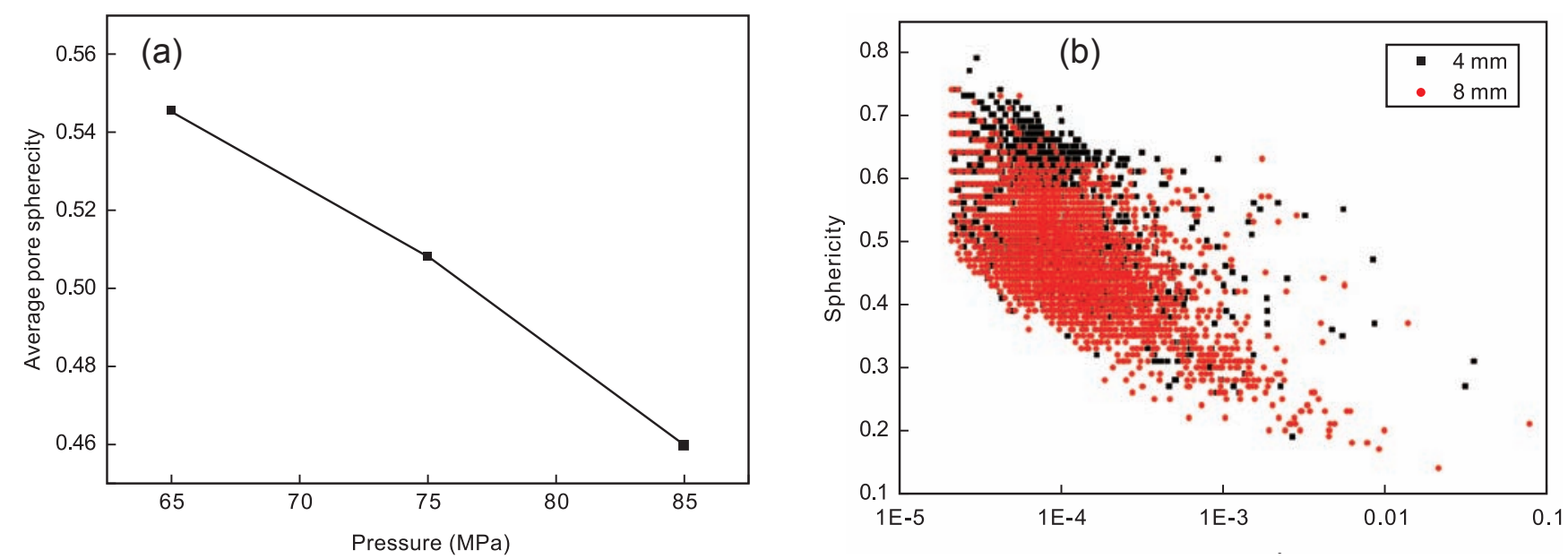

Fig. 7: Sphericity of pores: (a) in samples of $8 \mathrm{~mm}$ thickness at different intensification pressures, (b) in samples of $4 \mathrm{~mm}$ and $8 \mathrm{~mm}$ thicknesses under $75 \mathrm{MPa}$

gas pore reduced while the volumes of the biggest gas pores do not show apparent change. However, when the intensification pressure increases to $85 \mathrm{MPa}$, the number and volume of gas pores reduce rapidly (Table 2 ). This means that only if intensification pressure is great enough, gas pore number and size can be reduced. Figure 8 (b) shows that the higher intensification pressures reduced shrinkage pore volume.

To sum up, the increase of intensification pressure can apparently reduce shrinkage pore volumes, hence decreasing the whole pore volume. The pore number is mainly dependent on gas pores, and only a high enough intensification pressure can decrease the gas number as well as size.
Table 2: Data of different pore types in $8 \mathrm{~mm}$ samples

\begin{tabular}{ccccc}
$\begin{array}{c}\text { Pressure } \\
(\mathrm{MPa})\end{array}$ & $\begin{array}{c}\text { Volume of } \\
\text { shrinkage } \\
\left(\mathrm{mm}^{3}\right)\end{array}$ & $\begin{array}{c}\text { Number of } \\
\text { shrinkage } \\
(\mathbf{N})\end{array}$ & $\begin{array}{c}\text { Volume of } \\
\text { gas pore } \\
\left(\mathrm{mm}^{3}\right)\end{array}$ & $\begin{array}{c}\text { Number of } \\
\text { gas pore } \\
(\mathbf{N})\end{array}$ \\
\hline 85 & 0.767 & 1220 & 0.0321 & 953 \\
75 & 0.711 & 2201 & 0.210 & 3601 \\
65 & 1.216 & 1580 & 0.279 & 4572 \\
\hline
\end{tabular}

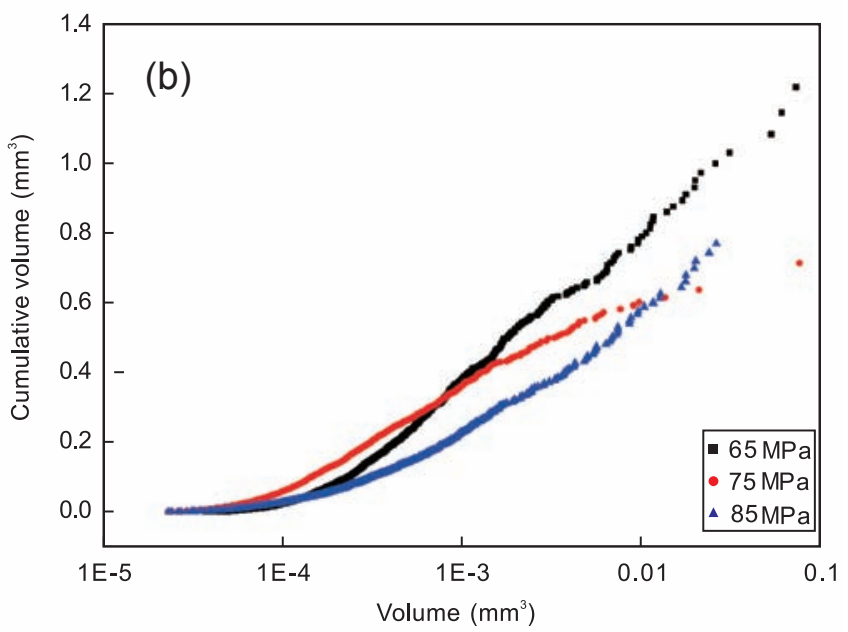

Fig. 8: Cumulative volumes of different pores in $8 \mathrm{~mm}$ samples: (a) gas pore, (b) shrinkage pore

\section{Conclusions}

(1) The increase of intensification pressure could compress the entrapped gases and strengthen liquid feeding, hence reducing porosity numbers and sizes in the investigated samples.
(2) The pressures didn't show obvious effect on pores in thin walled parts $(2 \mathrm{~mm})$. The reasons are that these parts solidify rapidly, which limits the transmission of intensification pressure. The pores in the parts are mainly controlled by entrapment of gases and oxide films during mold filling.

(3) As for relatively thick parts $(>4 \mathrm{~mm})$, the increase of 
intensification pressure can apparently reduce shrinkage pore volumes, hence decreasing the whole pore volume. The pore number is mainly dependent on gas pores, and only a high enough intensification pressure can decrease the gas number as well as size.

\section{References}

[1] Tisz M, Czinege A. Comparative study of the application of steels and aluminium in lightweight production of automotive parts. International Journal of Lightweight Materials and Manufacture, 2018, 1: 229-238.

[2] Farooq M A, Roth R, Kirchain R. Light weighting technologies: Analyzing strategic and economic implications of advanced manufacturing processes. International Journal of Production Economics, 2018, 206: 268-279.

[3] Okayasu M, Ota S K, Takeuchi H, et al. Influence of microstructural characteristics on mechanical properties of ADC12 aluminum alloy. Materials Science \& Engineering A, 2014, 592: 189-200.

[4] Outmani I, Fouilland-Paille L, Isselin J, et al. Effect of $\mathrm{Si}$, $\mathrm{Cu}$ and processing parameters on Al-Si-Cu HPDC castings, Journal of Materials Processing Technology, 2017, 249: 559569.

[5] Zhao H D, Wang F, Li Y Y, et al. Experimental and numerical analysis of gas entrapment defects in plate ADC12 die castings. Journal of Materials Processing Technology, 2009, 209: 4537-4542.

[6] Zhao H D, Bai Y F, Ouyang XX, et al. Simulation of mold filling and prediction of gas entrapment on practical high pressure die casting. Transactions of Nonferrous Metals Society of China, 2010, 20: 2064-2070.

[7] Savage G, Gershenzon M, Rogers K J. The role of pressure in high pressure die casting. In: Proceedings of the 21st International Die Casting Congress and Exposition. North American Die Casting Association, Cincinnati, Ohio, 2001: T1T53.

[8] Rogers K J, Savage G. In-cavity pressure sensors-errors, robustness and some process insights. Die Cast, Eng., 2000, 44 (5): 76-80.

[9] Dargusch M S, Dour G, Schauer N. The influence of pressure during solidification of high pressure die cast aluminium telecommunications components, Journal of Materials Processing Technology, 2006, 180(1-3): 37-43.

[10] Biswas S, Sket F, Chiumenti M, et, al. Relationship Between the 3D Porosity and $\beta$-Phase Distributions and the Mechanical Properties of a High Pressure Die Cast AZ91 Mg Alloy. Metallurgical \& Materials Transactions A, 2013, 44 (9): 43914403.

[11] Lee S G, Gokhale A M, Patel G R, et al. Effect of process parameters on porosity distributions in high-pressure die-cast AM50 Mg-alloy. Materials Science \& Engineering A, 2006, 427(1): 99-111.

[12] Lee S G, Gokhale A M. Visualization of three-dimensional pore morphologies in a high-pressure die-cast Mg-Al-RE alloy. Scripta Materialia, 2007, 56 (6): 501-504.

[13] Felberbaum M, Rappaz M. Curvature of micropores in $\mathrm{Al}-\mathrm{Cu}$ alloys: an X-ray tomography study. Acta Materialia, 2011, 59 (18): 6849-6860.

[14] Irfan M A, Schwam D, Karve A, et al. Porosity reduction and mechanical properties improvement in die cast engine blocks. Materials Science \& Engineering A, 2012, 535 (2): 108-114.

[15] Hangai $Y$, Kuwazuru $O$, Yano $T$ et al. Clustered Shrinkage Pores in III-Conditioned Aluminum Alloy Die Castings. Materials Transactions, 2015, 51 (9): 1574-1580.

[16] Kastner J, Harrer B, Degischer H P. High resolution cone beam X-ray computed tomography of 3D-microstructures of cast Alalloys. Materials Characterization, 2011, 62 (1): 99-107.

[17] Kuwazuru O, Murata Y, Hangai Y, et al. X-Ray CT Inspection for Porosities and Its Effect on Fatigue of Die Cast Aluminium Alloy. Journal of Solid Mechanics and Materials Engineering, 2008, 2(9): 1220-1231.

[18] Liu F, Zhao H, Yang R, et, al. Crack propagation behavior of die-cast AISiMgMn alloys with in-situ SEM observation and finite element simulation. Materials Today Communications, 2019, 19: 114-123.

[19] Tiryakioğlu M. Pore size distributions in AM50 Mg alloy die castings. Materials Science \& Engineering A, 2007, 465 (1-2): 287-289.

[20] Li X, Xiong S M, Guo Z. Correlation between Porosity and Fracture Mechanism in High Pressure Die Casting of AM60B Alloy. Journal of Materials Science \& Technology, 2016, 32(1): 54-61.

[21] Wan Q, Zhao H, Zou C. Three-dimensional characterization and distribution of micropores aluminum alloy high pressure die casting. Acta Metall Sin, 2013, 49: 284-290. 